\title{
Prevalence, comorbidity, disability and service
}

\section{utilisation}

\author{
Overview of the Australian National Mental Health Survey
}

GAVIN ANDREWS, SCOTT HENDERSON and WAYNE HALL

\author{
Background Health planning should \\ be based on data about prevalence, \\ disability and services used.
}

\begin{abstract}
Aims To determine the prevalence of ICD-10 disorders and associated comorbidity, disability and service utilisation.
\end{abstract}

\begin{abstract}
Method We surveyed a national probability sample of Australian households using the Composite International Diagnostic Interview and other measures.
\end{abstract}

Results The sample size was 10641 adults, response rate $78 \%$. Close to $23 \%$ reported at least one disorder in the past 12 months and $14 \%$ a current disorder. Comorbidity was associated with disability and service use. Only $35 \%$ of people with a mental disorder in the 12 months prior to the survey had consulted for a mental problem during that year, and most had seen a general practitioner. Only half of those who were disabled or had multiple comorbidity had consulted and of those who had not, more than half said they did not need treatment.

\section{Conclusions The high rate of not} consulting among those with disability and comorbidity is an important public health problem. As Australia has a universal health insurance scheme, the barriers to effective care must be patient knowledge and physician competence.

\section{Declaration of interest None.}

This report presents a detailed overview of the prevalence of mental and substance use disorders assessed in the 1997 Australian National Survey of Mental Health and Well-Being, the first national household survey to replicate and extend the 1990 US National Comorbidity Survey of adults aged 15-54 years (Kessler et al, 1994) and the 1993 UK Survey of Psychiatric Morbidity in adults aged 16-64 years (Jenkins et al, 1997a,b). All the surveys aimed to answer three questions: how many adults in private households had which mental disorder(s), how disabled were they by their disorder(s), and what health services they used and wanted. Australia has a national health insurance system and we hypothesised that the patterns of access to treatment by diagnosis, comorbidity and disability would be different from those in the US and similar to those in Britain. As in other surveys, a representative sample of adults living in private households were interviewed and cases were identified by lay interviewers using a structured interview. All three surveys collected data on service utilisation and disability to inform health care policy.

\section{METHOD}

\section{Sample}

The survey was conducted by the Australian Bureau of Statistics. The survey covered urban and rural areas across Australia. A multi-stage sample of private dwellings was drawn. Each state and territory was stratified and each dwelling within a stratum had an equal and known probability of selection. In all, 13624 private dwellings were initially selected in the survey sample, and one adult member aged 18 years or over randomly selected as the possible respondent; 1477 people refused, in 558 households contact could not be made with the identified respondent and in 948 households no interview occurred because the identified respondent could not communicate, there was death or illness in the household, or the interview was prematurely terminated. The sample did not include people in hospitals, nursing homes, hotels or jails, or residents of households in remote and sparsely settled parts of the country. For this reason Aborigines were undersampled and are not further identified. Ten thousand six hundred and fortyone people participated, a response rate of $78.1 \%$. The age and gender characteristics of the sample were weighted to match the age and gender distribution in the national census.

\section{Assessment}

The whole interview was administered from a laptop computer. The Composite International Diagnostic Interview (CIDI v2.1; World Health Organization, 1997; Andrews \& Peters, 1998) was used to determine, using ICD-10 (World Health Organization, 1992) and DSM-IV (American Psychiatric Association, 1994) criteria, the presence of six anxiety disorders (panic disorder, agoraphobia, social phobia (simple phobias were not identified), generalised anxiety disorder, obsessivecompulsive disorder, post-traumatic stress disorder), two affective disorders (major depression, dysthymia), four substance use disorders (alcohol dependence and misuse/ harmful use, drug dependence and misuse/ harmful use) and cognitive impairment (Mini-Mental State Examination (MMSE); Folstein et al, 1975). Screening questions were used to determine ICD-10 personality disorders (Loranger et al, 1997) and an interview for ICD-10 neurasthenia (Tacchini et al, 1995) was modified to reflect the Centers for Disease Control criteria for chronic fatigue syndrome (Hickie et al, 1997). The CIDI module for schizophrenia generates false positives in community samples and a five-item psychosis screener was used instead. People who met criteria for either cognitive impairment or psychosis on the screening questions are not included in analyses of chronicity, comorbidity, disability or service utilisation because of doubt about the probity of their reporting. A parallel survey of low-prevalence disorders has been conducted in four sites (Jablensky et al, 2000) and that prevalence estimate was consistent with the present data. Disability was measured at the beginning of the interview by the 12-item Short Form Health Survey (SF-12), a measure of 
functional impairment (Ware et al, 1996), and by the National Comorbidity Survey days-out-of-role questions. More detailed data on disability will be the focus of other papers. Perceived health need was based on the UK Survey of Psychiatric Morbidity questions.

\section{Interviewer training}

All interviewers were experienced staff from the Australian Bureau of Statistics. Supervisors for each State and Territory were trained at the World Health Organization Training and Reference Centre for CIDI in Sydney and then had a subsidiary course on how to train field staff.

\section{Data analysis}

Routine data analysis procedures were used but, as a result of the complex sample design and weighting, special software was required to estimate standard errors. The standard error of prevalence estimates and confidence intervals around odds ratios derived from logistic regression models were estimated using delete-one jackknife repeated replication in 30 design-based sub-samples (Kish \& Frankel, 1974). These calculations used the SUDAAN software package (Shah et al, 1997).

\section{RESULTS}

\section{Prevalence of psychiatric disorders}

The results in Table 1 show the ICD-10 and DSM-IV prevalence estimates for all 16 disorders in the past 1 and 12 months. DSM-IV data will not be further presented in tables, but can be obtained from G.A. The CIDI interview covered 12 anxiety, affective and substance use disorders. About one in six people in the community sample met criteria for any of the 12 ICD-10 (18.6\%) anxiety, affective or substance use disorders during the year (DSM-IV 15.5\%) and one in 11 met criteria in the month preceding the interview. Screening questions were used for the remaining diagnostic groups. Neurasthenia occurred in $1.5 \%$ of the sample, the screener for personality disorder was positive in $6.5 \%$, cognitive impairment (MMSE score less than 24$)$ in $1.3 \%$ (7.6\% in those aged 65 years and over) and the psychosis screener was positive in $0.4 \%$. Thus, the total prevalence in the past year of any mental disorder (ICD-10 plus the four screeners) was $22.7 \%$ and the

Table I Prevalence in the past I and I2 months of the major ICD-I0 and DSM-IV disorders, exclusion criteria operationalised

\begin{tabular}{|c|c|c|c|c|}
\hline \multirow[t]{3}{*}{ Disorders } & \multicolumn{2}{|c|}{ ICD-10 } & \multicolumn{2}{|c|}{ DSM-IV } \\
\hline & 12 month & I month & 12 month & I month \\
\hline & \% (s.e.) & \% (s.e.) & \% (s.e.) & \% (s.e.) \\
\hline \multicolumn{5}{|l|}{ Affective disorders } \\
\hline Major depression & $6.7(0.4)$ & $3.3(0.2)$ & $6.3(0.3)$ & $3.2(0.2)$ \\
\hline Dysthymia & $1.3(0.2)$ & I.I (0.2) & I.I (0.I) & $0.9(0.1)$ \\
\hline Any affective disorder & $7.2(0.4)$ & $3.8(0.2)$ & $6.6(0.4)$ & $3.5(0.2)$ \\
\hline \multicolumn{5}{|l|}{ Anxiety disorders } \\
\hline Panic disorder with/without agoraphobia & I.I (0.2) & $0.4(0.1)$ & I.I (0.I) & $0.5(0.1)$ \\
\hline Agoraphobia without panic disorder & I.I (0.2) & $0.8(0.1)$ & $0.5(0.1)$ & $0.2(0.0)$ \\
\hline Social phobia & $2.7(0.3)$ & $\mathrm{I} .4(0.1)$ & $1.3(0.1)$ & $1.0(0.1)$ \\
\hline Generalised anxiety disorder & $3.0(0.2)$ & $2.0(0.2)$ & $2.6(0.2)$ & $2.0(0.2)$ \\
\hline Obsessive-compulsive disorder & $0.3(0.1)$ & $0.3(0.1)$ & $0.7(0.1)$ & $0.5(0.1)$ \\
\hline Post-traumatic stress disorder & $3.3(0.2)$ & $1.7(0.2)$ & $1.3(0.1)$ & $0.9(0.1)$ \\
\hline Any anxiety disorder & $9.5(0.4)$ & $5.5(0.3)$ & $5.6(0.3)$ & $3.8(0.4)$ \\
\hline \multicolumn{5}{|l|}{ Substance use disorders } \\
\hline Alcohol harmful use/abuse & $3.0(0.3)$ & $0.7(0.2)$ & $1.9(0.2)$ & $0.7(0.1)$ \\
\hline Alcohol dependence & $3.5(0.5)$ & $\mathrm{I} .4(0.2)$ & $4.1(0.3)$ & $1.7(0.1)$ \\
\hline Drug harmful use/abuse & $0.2(0.1)$ & $<0.1(0.0)$ & $1.0(0.1)$ & $0.3(0.1)$ \\
\hline Drug dependence & $2.0(0.2)$ & $0.9(0.1)$ & $2.0(0.2)$ & $0.9(0.2)$ \\
\hline Any substance use disorder & $7.7(0.5)$ & $2.8(0.2)$ & $7.9(0.4)$ & $3.4(0.2)$ \\
\hline Any CIDI-defined ICD-I0/DSM-IV disorder & $18.6(0.5)$ & $9.5(0.4)$ & $15.5(0.5)$ & $8.5(0.4)$ \\
\hline \multicolumn{5}{|l|}{ Other disorders ${ }^{\prime}$} \\
\hline Neurasthenia & $1.5(0.2)$ & $1.2(0.2)$ & $\mathrm{I} .5(0.2)$ & $1.2(0.2)$ \\
\hline Any personality disorder & $6.5(0.3)$ & $5.3(0.3)$ & $6.5(0.3)$ & $5.3(0.3)$ \\
\hline Cognitive impairment & $1.3(0.1)$ & $1.3(0.1)$ & $1.3(0.1)$ & $1.3(0.1)$ \\
\hline Psychosis & $0.4(0.1)$ & $0.4(0.1)$ & $0.4(0.1)$ & $0.4(0.1)$ \\
\hline Any disorder & $22.7(0.6)$ & $13.9(0.5)$ & $20.3(0.6)$ & I3.2(0.4) \\
\hline
\end{tabular}

I. For these disorders screening questionnaires were used.

ICD-I0, World Health Organization (1992); DSM-IV, American Psychiatric Association (1994); CIDI, World Health Organization (1997).

corresponding DSM figure was $20.3 \%$. The corresponding prevalences for current cases or cases in the previous month were $13.9 \%$ and $13.2 \%$, respectively.

In the data above, the exclusion criteria were operationalised for the ICD and DSM CIDI diagnoses. If the exclusion criteria are not operationalised the prevalences rise by one or two percentage points. The prevalence of the 12 ICD-10 disorders in the previous 12 months rose from $18.6 \%$ to $19.4 \%$, and in DSM-IV from $15.5 \%$ to $17.1 \%$. In each case the change is wholly due to the influence of the exclusion criteria on the prevalences of the anxiety disorders. Affective and substance use disorder prevalences were unaffected by the exclusion criteria. DSM-IV contains a new criterion to assess clinical significance and this was operationalised in the CIDI interview. To examine the effect of this criterion it was deleted from the scoring algorithm.
Compared to the previous 12 month prevalence values in Table 1 , the previous 12 month prevalences without the clinical significance criteria were unchanged for the affective disorders, and all cases who otherwise met criteria agreed that the disorder caused clinically significant distress or impairment. It was unchanged in the substance use disorders but raised in the anxiety disorders (prevalence of any anxiety disorders 'with clinical significance' was $8.1 \%$, 'with and without clinical significance', 9.2\%). The overall DSM-IV prevalence in the previous 12 months for the 12 CIDI-defined disorders changed from $17.1 \%$ to $18 \%$. Thus, the clinical significance criterion makes a difference of $0.9 \%$.

\section{Demographic correlates}

Data are presented (Table $2 a$ ) for gender, age, marital status, country of birth, 
urbanicity, education and employment by disorder group (affective, anxiety, substance use disorders, any of the disorders, and any three or more of the 12 ICD-10/CIDIdefined disorders occurring in the past year). Univariate odds ratios and corresponding Wald $\chi^{2}$ estimates are provided for each variable. Each variable was then examined after controlling for the influence of all other variables on a disorder group (Table $2 b$ ). The results did not change significantly in the affective, anxiety and substance use disorder groups. Urbanicity ceased to be significant in the 'any disorder' group, and immigration status and education ceased to be significant in the group with three or more disorders.

\section{Gender}

Women had higher rates of affective and anxiety disorders and lower rates of substance use disorders than men. In total, the rates for any disorder or for a history of three or more disorders were not different between genders.

\section{Age}

The elderly had lower rates of all disorders except cognitive impairment, but as this was not ascertained in those under 65 the data are not reported. The young had much higher rates of substance use disorders.

\section{Marital status}

In general the currently married had lower rates for all disorders than those who had never married or were presently separated, divorced or widowed.

\section{Country of birth}

Migration showed no strong relationship to anxiety or depression, but was associated with a lower rate of substance use disorder.

\section{Urbanicity}

Urbanicity had no significant relationship with morbidity.

\section{Education}

In general, disorders were more frequent in those with less education.

\section{Employment}

Those in employment had lower rates of all disorders.

\section{Comorbidity}

In the remainder of the results, the denominator is the 12 CIDI-defined ICD-10 disorders plus the screeners for neurasthenia and personality disorder, that is, 14 disorders in all. Comorbidity, meeting criteria for more than one disorder in the 12 months before interview, was common. Twenty-one per cent of respondents met criteria for at least one of the 14 disorders in the previous 12 months, of these $13.2 \%$ reported one disorder, $4.4 \%$ two and $3.8 \%$ three or more (see Table 3 ). People with three or more disorders this year were 10 times more likely than people with one disorder to have a current disorder, six times more likely to have had a consultation for a mental problem this year, and seven times more likely to be moderately or severely disabled according to the SF-12 scores (Ware et al, 1996). People with two disorders had intermediate risks on all three measures. The results using the DSM-IV classification were similar.

\section{Chronicity}

The proportion of people who identified their symptoms as being present in the last month compared with the number who met criteria during the previous 12-month period is a measure of chronicity. Focusing on the 143 ICD-10 and screener diagnoses, $59 \%$ of cases in the past 12 months identified themselves as currently affected, with neurasthenia $(80 \%)$ and personality disorders $(82 \%)$ being most chronic, substance use disorders $(36 \%)$ most likely to remit, and the affective $(53 \%)$ and anxiety disorders $(58 \%)$ occupying some middle ground. The DSM-IV data are similar.

\section{Disability}

Disability was measured by the SF-12 and by asking about the number of disability days, both asked with respect to the past 4 weeks. We therefore relate those measures to current disorders or those in the past 30 days for the three groups of ICD-10 disorders and for neurasthenia and for personality disorders (see Table 4). In terms of both disability days and deficits in SF-12 scores, the affective disorders and neurasthenia were associated with the most disablement, and substance use and personality disorders the least. Again, as with chronicity, the anxiety disorders occupied the middle ground. The sum total of disability is an important indicator of the burden of any disease. When the mean numbers of disability days in Table 4 are multiplied by the prevalence in the past month of each disorder group in
Table 1 , the anxiety disorders account for $31 \%$, the affective disorders $27 \%$, the personality disorders $24 \%$, and the substance use disorders and neurasthenia each account for about $10 \%$ of the total disability days per month attributed to these five disorder groups. This calculation does not allow for comorbidity between disorder groups, which will be the topic of a separate paper.

\section{Health service utilisation}

In Australia, family physicians (general practitioners (GPs)) are the principal source of treatment for people with any disorder and are gatekeepers for insurance reimbursement for specialist services. Respondents were asked whether they had had a consultation for a mental problem in the past 12 months and whom they had consulted. Respondents were able to describe multiple sources of help but the categories in Table 5 are mutually exclusive. Restricting the analysis to people meeting criteria for any of the 14 disorders at some time during the previous 12 months, $35 \%$ reported a consultation for a mental health problem during the year, while $65 \%$ did not. Twenty-seven per cent saw a GP, that is, three-quarters of those consulting anyone for a mental health problem. Half $(13.2 \%)$ saw only the GP for their mental problem, the remainder saw the GP and another health professional as well, usually a mental health specialist (psychiatrist, psychologist, mental health team). Small numbers saw a mental health specialist only, or some other health professional only. Thus, in Australia as elsewhere, the GP is the key to treatment for most people with mental disorders.

We focus on comorbidity and disability in people with current disorders to examine the service utilisation of these high-need groups. We found that only $65 \%$ of people with multiple comorbidity with at least one current disorder had consulted a health professional for a mental problem during the year, $19 \%$ had consulted only a GP, $28 \%$ had consulted a mental health specialist with or without concurrent GP support, and $18 \%$ of this comorbid group had consulted only a health professional without any specific mental health training. We identify this as a serious mental health service delivery problem.

We also examined people who met criteria for a current diagnosis and who had SF-12 scores in moderate or severe ranges $(\mathrm{SF}-12<40)$. Forty-four per cent of 
Table 2a Unadjusted demographic correlates of ICD-10 (World Health Organization, 1992) psychiatric disorders in the past 12 months

\begin{tabular}{|c|c|c|c|c|c|c|c|c|c|c|c|}
\hline & \multirow{3}{*}{$\begin{array}{l}\text { Sample } \\
\text { size }(n)\end{array}$} & \multicolumn{10}{|c|}{ ICD-I0 disorders } \\
\hline & & \multicolumn{2}{|c|}{$\begin{array}{l}\text { Any affective disorder } \\
\qquad(n=868)\end{array}$} & \multicolumn{2}{|c|}{$\begin{array}{c}\text { Any anxiety disorder } \\
\qquad(n=1118)\end{array}$} & \multicolumn{2}{|c|}{$\begin{array}{l}\text { Any substance use } \\
\text { disorder }(n=8 \mid 8)\end{array}$} & \multicolumn{2}{|c|}{$\begin{array}{l}\text { Any disorder } \\
(n=2076)\end{array}$} & \multicolumn{2}{|c|}{$\begin{array}{c}\geqslant 3 \text { disorders } \\
(n=288)\end{array}$} \\
\hline & & Odds ratio & $95 \% \mathrm{Cl}$ & Odds ratio & $95 \% \mathrm{Cl}$ & Odds ratio & $95 \% \mathrm{Cl}$ & Odds ratio & $95 \% \mathrm{Cl}$ & Odds ratio & $95 \% \mathrm{Cl}$ \\
\hline \multicolumn{12}{|l|}{ Gender } \\
\hline Male & 4705 & 1.0 & - & 1.0 & - & 1.0 & - & 1.0 & - & 1.0 & - \\
\hline Female & 5936 & $1.8 * *$ & $1.5-2.2$ & $1.8^{* *}$ & $1.4-2.4$ & $0.4^{* *}$ & $0.3-0.5$ & 1.1 & $0.8-1.4$ & 1.3 & $0.8-1.9$ \\
\hline$\chi_{1}^{2}(P)$ & & 40.6 & $<0.001$ & 20.7 & $<0.001$ & 59.5 & $<0.001$ & 0.5 & 0.495 & 1.3 & 0.247 \\
\hline \multicolumn{12}{|l|}{ Age, years } \\
\hline $18-24$ & 1069 & 1.0 & - & 1.0 & - & 1.0 & - & 1.0 & - & 1.0 & - \\
\hline $25-34$ & 2189 & 1.0 & $0.8-1.3$ & 0.9 & $0.7-1.1$ & $0.7^{*}$ & $0.5-0.9$ & $0.8^{*}$ & $0.6-1.0$ & 0.8 & $0.5-1.5$ \\
\hline $35-44$ & 2480 & 1.1 & $0.8-1.4$ & 1.0 & $0.7-1.5$ & $0.5^{* *}$ & $0.3-0.7$ & $0.7^{*}$ & $0.6-0.9$ & 0.9 & $0.5-1.7$ \\
\hline $45-54$ & 1832 & 1.0 & $0.8-1.4$ & 1.1 & $0.8-1.5$ & $0.3 * *$ & $0.2-0.4$ & $0.6 *$ & $0.5-0.8$ & 1.0 & $0.6-1.7$ \\
\hline $55-64$ & 1279 & 0.8 & $0.5-1.2$ & $0.7^{*}$ & $0.5-0.9$ & $0.2 * *$ & $0.1-0.2$ & $0.4^{* *}$ & $0.3-0.5$ & 0.5 & $0.2-1.5$ \\
\hline$>65$ & 1792 & $0.3^{* *}$ & $0.2-0.4$ & $0.4^{* *}$ & $0.3-0.5$ & $0.1 * *$ & $0.0-0.1$ & $0.2^{* *}$ & $0.2-0.2$ & $0.1 * *$ & $0.0-0.2$ \\
\hline$\chi_{5}^{2}(P)$ & & 67.0 & $<0.001$ & 64.2 & $<0.001$ & 239.8 & $<0.001$ & 260.2 & $<0.001$ & 24.6 & $<0.001$ \\
\hline \multicolumn{12}{|l|}{ Marital status } \\
\hline Married/de facto & 6324 & 1.0 & - & 1.0 & - & 1.0 & - & 1.0 & - & 1.0 & - \\
\hline Separated/divorced/widowed & 2255 & $1.8^{*}$ & $1.2-2.7$ & $1.7 * *$ & $1.3-2.2$ & 1.3 & $0.8-2.2$ & $1.5^{*}$ & $1.1-2.1$ & $2.4^{* *}$ & $1.7-3.3$ \\
\hline Never married & 2062 & $1.4^{*}$ & $1.1-1.8$ & $1.3^{*}$ & $1.1-1.6$ & $3.7^{* *}$ & $3.0-4.5$ & $2.0 * *$ & $1.7-2.3$ & $2.5^{* *}$ & $1.8-3.3$ \\
\hline$\chi_{2}^{2}(P)$ & & 10.8 & 0.005 & 33.6 & $<0.001$ & 191.5 & $<0.001$ & 119.6 & $<0.001$ & 56.9 & $<0.001$ \\
\hline \multicolumn{12}{|l|}{ Country of birth } \\
\hline Australia & 8130 & 1.0 & - & 1.0 & - & 1.0 & - & 1.0 & - & 1.0 & - \\
\hline Other English-speaking country & $125 \mid$ & 0.7 & $0.4-1.1$ & 0.9 & $0.7-1.1$ & 0.8 & $0.6-1.1$ & 0.8 & $0.6-1.1$ & $0.6^{*}$ & $0.4-1.0$ \\
\hline \multicolumn{12}{|l|}{ Other non-English-speaking } \\
\hline country & 1260 & 0.9 & $0.7-1.3$ & 1.0 & $0.8-1.2$ & $0.4^{* *}$ & $0.3-0.6$ & $0.8^{*}$ & $0.7-0.9$ & 0.7 & $0.5-1.1$ \\
\hline$\chi_{2}^{2}(P)$ & & 2.9 & 0.230 & 1.4 & 0.507 & 21.0 & $<0.001$ & 7.3 & 0.026 & 7.2 & 0.027 \\
\hline \multicolumn{12}{|l|}{ Urbanicity } \\
\hline Urban & 7137 & 1.0 & - & 1.0 & - & 1.0 & - & 1.0 & - & 1.0 & - \\
\hline Rural centre & 1562 & 1.2 & $0.9-1.5$ & $1.2^{*}$ & $1.0-1.4$ & 1.0 & $0.8-1.3$ & 1.1 & $0.9-1.2$ & 1.3 & $0.8-2.3$ \\
\hline Other rural area ${ }^{2}$ & 1942 & 0.8 & $0.6-1.2$ & 0.8 & $0.6-1.1$ & 0.8 & $0.6-1.1$ & $0.8^{*}$ & $0.7-1.0$ & 0.8 & $0.5-1.4$ \\
\hline$\chi_{2}^{2}(P)$ & & 2.3 & 0.323 & 8.3 & 0.015 & 2.8 & 0.250 & 6.6 & 0.037 & 1.2 & 0.544 \\
\hline \multicolumn{12}{|l|}{ Education } \\
\hline Bachelor degree or above & 1579 & 1.0 & - & 1.0 & - & 1.0 & - & 1.0 & - & 1.0 & - \\
\hline Diploma & 1049 & 1.0 & $0.5-1.7$ & 1.3 & $0.9-1.9$ & 0.8 & $0.5-1.2$ & 1.1 & $0.8-1.4$ & 0.8 & $0.3-2.1$ \\
\hline Vocational qualification & 2379 & 1.3 & $0.9-1.8$ & $1.7^{*}$ & $1.2-2.4$ & 1.2 & $0.9-1.5$ & $1.4^{*}$ & $1.1-1.9$ & 1.6 & $0.8-3.1$ \\
\hline High school only & 5634 & $1.5^{*}$ & $1.0-2.2$ & $1.7 *$ & $1.3-2.3$ & 1.1 & $0.9-1.5$ & $1.5^{* *}$ & $1.3-1.8$ & 1.8 & $0.9-3.6$ \\
\hline$\chi_{3}^{2}(P)$ & & 17.4 & 0.001 & 16.1 & 0.001 & 4.7 & 0.193 & 33.2 & $<0.001$ & 9.2 & 0.027 \\
\hline \multicolumn{12}{|l|}{ Employment } \\
\hline Employed & 6490 & 1.0 & - & 1.0 & - & 1.0 & - & 1.0 & - & 1.0 & - \\
\hline Short-term unemployed ${ }^{3}$ & 279 & $2.1^{*}$ & $1.4-3.2$ & $2.2^{*}$ & $1.4-3.6$ & $2.7^{* *}$ & $1.7-4.5$ & $2.1 * *$ & $1.5-2.9$ & $5.2^{* *}$ & $2.7-10.1$ \\
\hline Long-term unemployed ${ }^{4}$ & 159 & $2.4^{*}$ & $1.4-4.3$ & $2.8^{*}$ & $1.6-5.0$ & $2.3^{*}$ & $1.4-3.7$ & $2.8^{* *}$ & $2.0-4.1$ & $5.0^{*}$ & $2.1-12.1$ \\
\hline Not in labour force & 3713 & 1.2 & $1.0-1.5$ & $1.3 *$ & $1.1-1.4$ & $0.4^{* *}$ & $0.4-0.6$ & 0.9 & $0.8-1.0$ & 1.3 & $0.7-2.3$ \\
\hline$\chi_{3}^{2}(P)$ & & 23.8 & $<0.001$ & 21.3 & $<0.001$ & 124.7 & $<0.001$ & 85.1 & $<0.001$ & 38.6 & $<0.001$ \\
\hline
\end{tabular}

Exclusion criteria are operationalised. $* P<0.05, * * P<0.001$.

I. Rural area: population between $10000-100000$.

2. Rural area: population $<10000$.

3. Unemployed $<12$ months.

4. Unemployed $\geqslant 12$ months. 
Table $2 b$ Adjusted demographic correlates of ICD-10 (World Health Organization, 1992) in the past 12 months

\begin{tabular}{|c|c|c|c|c|c|c|c|c|c|c|c|}
\hline & \multirow{3}{*}{$\begin{array}{l}\text { Sample } \\
\text { size }(n)\end{array}$} & \multicolumn{10}{|c|}{ ICD-I0 disorders } \\
\hline & & \multicolumn{2}{|c|}{$\begin{array}{l}\text { Any affective disorder } \\
\qquad(n=868)\end{array}$} & \multicolumn{2}{|c|}{$\begin{array}{l}\text { Any anxiety disorder } \\
\qquad(n=1118)\end{array}$} & \multicolumn{2}{|c|}{$\begin{array}{l}\text { Any substance use } \\
\text { disorder }(n=8 \mid 8)\end{array}$} & \multicolumn{2}{|c|}{$\begin{array}{l}\text { Any disorder } \\
(n=2076)\end{array}$} & \multicolumn{2}{|c|}{$\begin{array}{c}\geqslant 3 \text { disorders } \\
(n=288)\end{array}$} \\
\hline & & Odds ratio & $95 \% \mathrm{Cl}$ & Odds ratio & $95 \% \mathrm{Cl}$ & Odds ratio & $95 \% \mathrm{Cl}$ & Odds ratio & $95 \% \mathrm{Cl}$ & Odds ratio & $95 \% \mathrm{Cl}$ \\
\hline \multicolumn{12}{|l|}{ Gender } \\
\hline Male & 4705 & 1.0 & - & 1.0 & - & 1.0 & - & & & & \\
\hline Female & 5936 & $1.7^{* *}$ & $1.4-2.0$ & $1.7 * *$ & $1.3-2.1$ & $0.4^{* *}$ & $0.3-0.5$ & & & & \\
\hline$\chi_{1}^{2}(P)$ & & 30.0 & $<0.001$ & 21.2 & $<0.001$ & 63.6 & $<0.001$ & & & & \\
\hline \multicolumn{12}{|l|}{ Age, years } \\
\hline $18-24$ & 1069 & 1.0 & - & 1.0 & - & 1.0 & - & 1.0 & - & 1.0 & - \\
\hline $25-34$ & 2189 & 1.3 & $0.9-1.7$ & 1.0 & $0.7-1.6$ & 1.0 & $0.6-1.6$ & 1.0 & $0.8-1.3$ & 1.4 & $0.7-2.9$ \\
\hline $35-44$ & 2480 & 1.4 & $0.9-2.1$ & 1.3 & $0.7-2.4$ & 0.8 & $0.5-1.2$ & 1.0 & $0.8-1.2$ & 1.9 & $0.8-4.5$ \\
\hline $45-54$ & 1832 & 1.3 & $0.9-2.0$ & 1.3 & $0.9-2.0$ & 0.5 & $0.2-1.1$ & 0.8 & $0.6-I . I$ & $2.1^{*}$ & I.I-4.2 \\
\hline $55-64$ & 1279 & 0.8 & $0.5-1.2$ & $0.6 *$ & $0.4-1.0$ & $0.2^{* *}$ & $0.2-0.4$ & $0.4^{* *}$ & $0.3-0.6$ & 0.8 & $0.2-2.4$ \\
\hline$>65$ & 1792 & $0.2^{* *}$ & $0.1-0.3$ & $0.2^{* *}$ & $0.2-0.4$ & $0.1 * *$ & $0.0-0.1$ & $0.2^{* *}$ & $0.1-0.2$ & $0.1 * *$ & $0.0-0.2$ \\
\hline$\chi_{5}^{2}(P)$ & & 58.2 & $<0.001$ & 81.0 & $<0.001$ & 170.8 & $<0.001$ & 218.5 & $<0.001$ & 66.3 & $<0.001$ \\
\hline \multicolumn{12}{|l|}{ Marital status } \\
\hline Married/de facto & 6324 & 1.0 & - & 1.0 & - & 1.0 & - & 1.0 & - & 1.0 & - \\
\hline Separated/divorced/widowed & 2255 & $2.0^{*}$ & $1.3-3.1$ & $1.9 * *$ & I.5-2.4 & $2.3^{* *}$ & 1.7-3.3 & $2.0 * *$ & $1.5-2.5$ & $2.8^{* *}$ & $2.1-3.9$ \\
\hline Never married & 2062 & $1.4^{*}$ & $1.1-1.9$ & 1.3 & $1.0-1.8$ & $2.1 * *$ & $1.6-2.7$ & $1.5^{* *}$ & $1.3-1.8$ & $2.5^{* *}$ & $1.7-3.8$ \\
\hline$\chi_{2}^{2}(P)$ & & 14.3 & 0.001 & 48.0 & $<0.001$ & 47.3 & $<0.001$ & 48.9 & $<0.001$ & 69.7 & $<0.001$ \\
\hline \multicolumn{12}{|l|}{ Country of birth } \\
\hline Australia & 8130 & & & & & 1.0 & - & 1.0 & - & & \\
\hline Other English-speaking country & $|25|$ & & & & & 1.0 & $0.7-1.4$ & 0.9 & $0.7-1.2$ & & \\
\hline \multicolumn{12}{|l|}{ Other non-English-speaking } \\
\hline country & 1260 & & & & & $0.4 * *$ & $0.3-0.6$ & $0.8^{*}$ & $0.6-1.0$ & & \\
\hline$\chi_{2}^{2}(P)$ & & & & & & 28.8 & $<0.001$ & 6.6 & 0.037 & & \\
\hline \multicolumn{12}{|l|}{ Urbanicity } \\
\hline Urban & 7137 & & & & & & & & & & \\
\hline Rural centre ${ }^{l}$ & 1562 & & & & & & & & & & \\
\hline Other rural area ${ }^{2}$ & 1942 & & & & & & & & & & \\
\hline \multicolumn{12}{|l|}{$\chi_{2}^{2}(P)$} \\
\hline \multicolumn{12}{|l|}{ Education } \\
\hline Bachelor degree or above & 1579 & 1.0 & - & 1.0 & - & & & 1.0 & - & & \\
\hline Diploma & 1049 & 1.0 & $0.6-1.7$ & 1.3 & $0.9-1.9$ & & & 1.2 & $0.9-1.6$ & & \\
\hline Vocational qualification & 2379 & 1.3 & $0.9-2.0$ & $1.8^{*}$ & $1.3-2.5$ & & & $1.5^{*}$ & $1.1-2.0$ & & \\
\hline High school only & 5634 & $1.5^{*}$ & $1.0-2.2$ & $1.6 *$ & I.2-2.I & & & $1.6 * *$ & $1.3-1.8$ & & \\
\hline$\chi_{3}^{2}(P)$ & & II.I & 0.011 & 14.4 & 0.002 & & & 36.3 & $<0.001$ & & \\
\hline \multicolumn{12}{|l|}{ Employment } \\
\hline Employed & 6490 & 1.0 & - & 1.0 & - & 1.0 & - & 1.0 & - & 1.0 & - \\
\hline Short-term unemployed ${ }^{3}$ & 279 & $1.9 *$ & $1.3-2.9$ & $2.0^{*}$ & $1.2-3.4$ & $1.8^{*}$ & I.I-3.I & $1.6 *$ & $1.1-2.3$ & $4.2^{* *}$ & $2.1-8.4$ \\
\hline Long-term unemployed ${ }^{4}$ & 159 & $2.1 *$ & I.I-3.8 & $2.5^{*}$ & $1.4-4.5$ & $2.3^{*}$ & $1.3-4.0$ & $2.6 * *$ & $1.8-3.8$ & $4.0^{*}$ & $1.6-10.3$ \\
\hline Not in labour force & 3713 & $1.6^{*}$ & I.2-2.2 & $1.7 * *$ & $1.4-2.2$ & 1.2 & $0.9-1.6$ & $1.6 * *$ & $1.3-1.9$ & $2.3^{*}$ & I.2-4.4 \\
\hline$\chi_{3}^{2}(P)$ & & 24.1 & $<0.001$ & 32.0 & $<0.001$ & 13.3 & 0.004 & 38.5 & $<0.001$ & 41.7 & $<0.001$ \\
\hline
\end{tabular}

Exclusion criteria are operationalised. $* P<0.05, * * P<0.001$.

I. Rural area: population between $10000-100000$.

2. Rural area: population $<10000$

3. Unemployed $<12$ months.

4. Unemployed $\geqslant 12$ months. 
Table 3 Relationship between comorbidity, current disorder, service utilisation and disability for persons with one or more ICD-I0 (World Health Organization, 1992) disorders in the previous 12 months

\begin{tabular}{|c|c|c|c|c|c|c|c|}
\hline \multirow[t]{2}{*}{ Number of ICD-10 disorders } & \multirow{2}{*}{$\begin{array}{c}\begin{array}{c}\text { Proportion of } \\
\text { sample }\end{array} \\
\% \text { (s.e.) }\end{array}$} & \multicolumn{2}{|c|}{$\begin{array}{l}\text { Proportion with current } \\
\text { disorder' }\end{array}$} & \multicolumn{2}{|c|}{$\begin{array}{l}\text { Proportion with at least one mental } \\
\text { health consultation }{ }^{2}\end{array}$} & \multicolumn{2}{|c|}{$\begin{array}{l}\text { Proportion with any disability on } \\
\text { the SF- } 12^{3}\end{array}$} \\
\hline & & \% (s.e.) & Odds ratio $(\mathrm{Cl})$ & \% (s.e.) & Odds ratio $(\mathrm{Cl})$ & \% (s.e.) & Odds ratio $(\mathrm{Cl})$ \\
\hline None & $78.6(0.5)$ & - & - & - & - & $6.0(0.4)$ & $0.2(0.2-0.3)$ \\
\hline One & $13.2(0.5)$ & $45.7(1.9)$ & 1.0 & $22.4(1.2)$ & 1.0 & $21.0(I . I)$ & 1.0 \\
\hline Two & $4.4(0.3)$ & $71.9(2.8)$ & $3.1(2.2-4.2)$ & $46.0(2.7)$ & $2.9(2.3-3.8)$ & $39.5(4.4)$ & $2.5(1.8-3.5)$ \\
\hline Three or more & $3.8(0.2)$ & $89.1(1.5)$ & $9.7(6.9-13.8)$ & $64.0(2.3)$ & $6.2(4.8-7.9)$ & $63.5(2.8)$ & $6.6(5.2-8.3)$ \\
\hline
\end{tabular}

Exclusion criteria are operationalised. $* P<0.05, * * p<0.001$.

I. Defined as having symptoms in the past 4 weeks.

2. Defined as consulting any health professional for mental health problems in the past 12 months.

3. Defined as scoring more than one standard deviation below the mean for the general population on the SF-12 (Ware et al, 1996) mental health summary scale (less than 40.00).

Table 4 Mean disability days and SF-12 (Ware et al, 1996) scores for current ICD-10 (World Health Organization, 1992) disorder groups

\begin{tabular}{lccc}
\hline Disorder group & Disability days & & $\begin{array}{c}\text { SF-12 mental } \\
\text { summary scale }\end{array}$ \\
\cline { 2 - 3 } & Mean (s.e.) & Mean (s.e.) \\
\hline Affective disorders & $11.7(0.7)$ & $33.4(0.7)$ \\
Anxiety disorders & $9.2(0.6)$ & $38.7(0.5)$ \\
Substance use disorders & $5.2(0.5)$ & $44.4(0.7)$ \\
Personality disorders & $7.4(0.5)$ & $42.0(0.6)$ \\
Neurasthenia & $14.0(1.3)$ & $34.6(1.2)$ \\
Any of the above disorders & $7.4(0.4)$ & $41.7(0.4)$ \\
\hline
\end{tabular}

I. Defined as the number of days in the past 4 weeks where the respondent was completely unable to carry out or had to cut down on their usual activities owing to their health.

Table 5 Utilisation of professional services for mental health problems for people with and without ICD-10 (World Health Organization 1992) disorders in the past 12 months

\begin{tabular}{lccr}
\hline Type of professional seen & $\begin{array}{c}\text { No disorder } \\
\%(\text { s.e. }\end{array}$ & $\begin{array}{c}\text { Any disorder } \\
\%(\text { s.e. }\end{array}$ & $\begin{array}{c}\geqslant 3 \text { disorders } \\
\%(\text { s.e.) }\end{array}$ \\
\hline General practitioner only' & $2.2(0.2)$ & $13.2(1.0)$ & $18.1(2.2)$ \\
Mental health professional only ${ }^{2}$ & $0.5(0.1)$ & $2.4(0.3)$ & $3.9(0.8)$ \\
Other health professional only $^{3}$ & $1.0(0.1)$ & $4.0(0.6)$ & $5.7(1.1)$ \\
Combination of health professionals $_{\text {Any health professional }}{ }^{2}$ & $1.0(0.1)$ & $15.0(0.8)$ & $36.4(3.1)$ \\
\hline
\end{tabular}

All data refer to consultations for mental health problems.

I. Refers to persons who had at least one consultation with a general practitioner in the previous 12 months but did not consult any other type of health professional.

2. Refers to persons who had at least one consultation with a mental health professional (psychiatrist/psychologist/ mental health team) in the previous 12 months but did not consult any other type of health professional.

3. Refers to persons who had at least one consultation with another health professional (nurse/non-psychiatric medical specialist/pharmacist/ambulance officer/welfare worker or counsellor) in the previous 12 months but did not consult any other type of health professional.

4. Refers to persons who had at least one consultation with any health professional in the previous 12 months.

people with a current mental disorder were disabled to this extent, and only $55 \%$ of this group had consulted any health professional for a mental problem. There is considerable overlap between disablement and comorbidity and the precise relationships in the current cases are illustrated in Fig. 1. If those people with multiple comorbidity this year, or with moderate or severe disability this month, are considered as a group as those who warrant treatment, then $44 \%$ of this group did not consult for a mental problem in the previous 12 months. In the interview they were reminded of their symptoms and that they had not mentioned getting help, and asked "were there types of help you needed?” Asked specifically why they had not sought "medication or tablets" or "counselling or talking therapy", treatments of potential efficacy, $59 \%$ of this no-treatment group replied that they did not need such treatment.

\section{DISCUSSION}

\section{Survey}

The size (10641) and response rate (78\%) were comparable to the other national surveys (UK: 10108, 80\%, Jenkins et al, 1997a; US: 8098, 82\%, Kessler et al, 1994) but as the morbidity in the non-responders is likely to be higher than among the responders (Kessler et al, 1995), all prevalences will be underestimates. The real prevalence of a mental disorder is difficult to determine because the identification of mental disorders is imprecise. While the advent of the fully specified DSM and ICD classifications was a considerable advance for psychiatry, at best these criteria are surface representations of what specialist clinicians believe to be the underlying disease construct, and usually define a category by placing a cut on a dimension of symptoms (Andrews, 2000a). Fully structured diagnostic interviews, such as the CIDI and the screening instruments used in the present survey, simply operationalise these diagnostic criteria into questions 


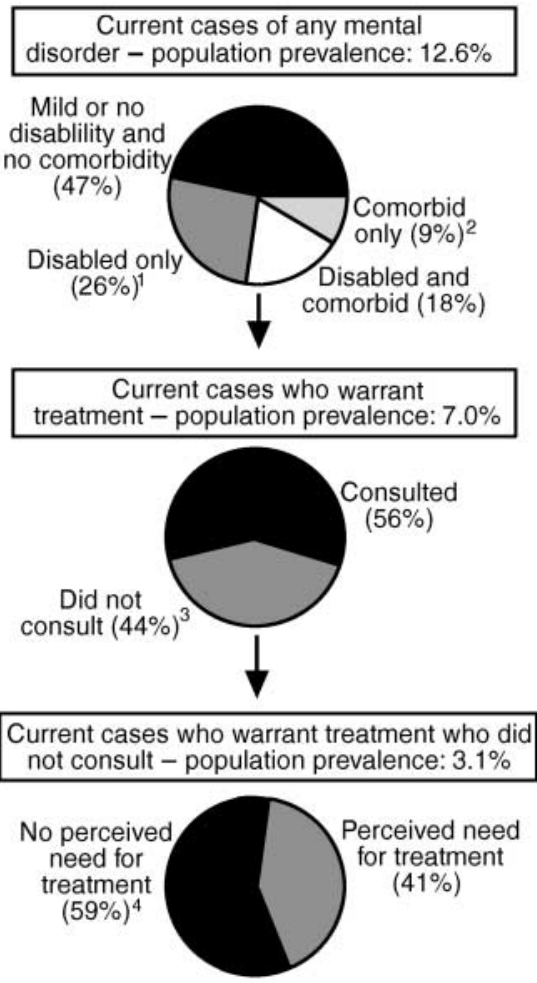

Fig. I Service utilisation and perceived need for treatment in current cases. Current cases refer to persons meeting criteria for any ICD-10 anxiety, affective or substance use disorder, personality disorder or neurasthenia in the past month.

I. Defined as having an SF-12 mental health summary scale score less than 40 .

2. Defined as having two additional diagnoses during previous year.

3. No consultations for a mental health problem during previous year.

4. No perceived need for medicines or counselling.

comprehensible to the average respondent, but the extent to which they are understood in the manner intended will vary from respondent to respondent.

In the present study, the computer program ensured that the logic of the interview was maintained and that all responses were in range. The CIDI v2.1 is much quicker than CIDI v1.1, and contains skips whenever it is impossible for the particular criteria to be met. The screeners and other material in the survey were similarly constructed and constrained by the need for the interview to be brief. The mean duration of the CIDI section was 30 minutes, comparable to the Clinical Interview Schedule-Revised in the UK survey, and the whole interview was 50 minutes (median 46 minutes). Drop-outs, once the interview had begun, were extremely rare (less than $0.1 \%$ ).
One in five Australian adults met criteria for a common mental disorder in the previous year, one in seven in the previous month. The disorders varied in their apparent chronicity, that is, personality disorders and neurasthenia were least likely to remit during the year, and substance use disorders most likely to remit during the year. The prevalence rates generated by the DSM-IV classification were lower than in ICD-10. This was not just due to the new clinical significance criterion in DSM-IV. In this study, it and the exclusion criteria affected the prevalence only of the anxiety disorders. The overall effect of the former was small and it would simplify discussion of the characteristics of a disorder if clinical significance were to be omitted in DSM-V (Spitzer \& Wakefield, 1999). There is no scientific reason or precedent in physical medicine why all people with a disorder should report disability: it would simply be convenient for research on psychiatric nosology and for health service planning if this were so. The exclusion criteria in ICD-10 or DSM-IV are inconsistent (Andrews, 2000a) and also need to be reviewed.

\section{Comparison with the other surveys}

Jenkins et al (1997b) reported that in any week, $16 \%$ of the UK population aged 16-64 met criteria for an ICD-10 anxiety or depressive disorder, and that in any year $4.7 \%$ had alcohol dependence and $2.2 \%$ drug dependence. If these data are adjusted onto a 1-year time-frame using chronicity and comorbidity information from the present survey (an imprecise way of proceeding) then the total prevalence in the past 12 months for any ICD-10 anxiety, affective or substance use disorder is of the order of $27 \%$ of the population. Kessler et al (1994) reported that $29 \%$ of Americans (age range 15-54 years and no exclusion criteria operating) met criteria for a DSM-III-R (American Psychiatric Association, 1987) affective, anxiety or substance use disorder in the past 12 months. In the present survey the comparable figure, with age range 18-64 and no exclusion criteria operating, was $22 \%$. Are the three sets of prevalences different? The Australian figure would increase if the clinical significance criterion was not included, if adjustments had been made for non-respondents, if Kessler commitment and stem probes had been used, and if simple phobia and mania had been added to the range of diagnoses identified. We are not able to conclude that the total prevalence of these mental disorders in Australia is less than that in the UK or the USA. Differences in particular diagnoses may be identified in subsequent analyses. The demographic correlates of diagnosis in the three surveys were similar, in direction and in size of odds ratios. Even if the prevalence figures are different, the nature of the disorders identified are likely to be the same. An examination of comorbidity, disability and health service utilisation confirms this finding. People with more than one disorder in the previous 12 months were more likely to be currently ill, more likely to consult and more likely to be disabled; for people with more than two disorders these factors were considerably more likely. Affective and anxiety disorders and neurasthenia were the most disabling disorders, personality and substance use disorders less so.

\section{Reducing the burden of disease}

The World Health Organization Burden of Disease study estimated that mental disorders, including dementia, accounted for $22 \%$ of the total burden of disease in established market economies. That study took no account of comorbidity and to that extent the burden of the mental disorders would have been an overestimate (Andrews et al, 1998). Preliminary prevalence figures from the present survey were used to inform the Australian Burden of Disease study (Mathers et al, 1999), which made method changes including adjusting for comorbidity by dividing the disability weight by the number of comorbid disorders. They concluded that the burden of mental disorders was $15 \%$ of the total burden, third in importance after heart disease and cancer.

Reducing the burden of disease requires efficacious treatments. Systematic reviews of treatment efficacy in single disorders have been commonplace (Nathan \& Gorman, 1998), but at the time of completion of the UK and US surveys there were few reviews of treatment efficacy in people with the comorbid disorders. The situation is changing. There is now a literature on the management of people with substance use disorders and concurrent anxiety and affective disorders (Scott et al, 1998). The literature on the treatment of people with concurrent anxiety and affective disorders is developing (Woody et al, 1999), and this is important given the strong contribution 
that comorbidity between anxiety and depression makes to the total disability attributed to mental disorders (Andrews et al, 2000). Unfortunately, clinical practice guidelines, which are the principal means of introducing research findings into practice, still tend to be focused on the management of people with a single disorder, whereas the reality of clinical practice is different. Many funding systems are equally restrictive. A major conclusion of this survey is that too many people with current comorbid and disabling disorders are going without specialist treatment. The results of this survey, like those of the UK and US surveys, emphasise that a concerted effort is needed to move the new research findings on treatment of comorbid and disabling disorders into clinical practice.

\section{Service delivery}

Health surveys should inform service delivery, and prevalence and disability data should pinpoint the groups of people with the greatest need for treatment. Australia spends $0.425 \%$ of its gross domestic product on mental health, less per capita than most developed countries, and therefore the task of focusing the resources available is even more critical. There has been much discussion about who should be treated (Regier $e t$ al, 1993; Andrews \& Henderson, 2000) and there is wide acceptance that no country can afford, or indeed has the trained staff, to offer treatment to the one in seven citizens who meet criteria for a current mental disorder. Some form of triage system seems to be necessary. Kessler et al (1994) and Jenkins et al (1997b) both report data on the importance of comorbidity as a determinant of disability and health service utilisation. On the basis of data in the present survey, we agree, but also note the frequency with which moderate or severe disability is also associated with single disorders.

Only $35 \%$ of people with a mental disorder during the year preceding our study had consulted a doctor for a 'mental problem', $65 \%$ had not. The rates in the UK are similar, the rates in the USA half this (Andrews, 2000b). GPs were the principal caregivers, either alone or in collaboration with other health professionals. Thirtyfive per cent of people with multiple comorbidity and $44 \%$ of people with moderate or severe disability had not sought a consultation, mostly because they saw no need. Despite a national health insurance scheme there are profound deficits in

\section{CLINICAL IMPLICATIONS}

- One in seven adults meets criteria for a current mental disorder, and one in 15 is moderately or severely disabled by a current mental disorder. Clinicians, in particular general practitioners, should be aware of this.

Despite the availability of effective treatment, anxiety and depressive disorders remain the principal cause of the disability produced by mental disorders.

Half the people with a disorder did not seek help, not realising how well they could become. The profession should undertake public education.

\section{LIMITATIONS}

Structured diagnostic interviews are not the same as judgement by a clinician. They are more reliable, but rely on self-report which lay interviewers cannot evaluate.

Prevalence estimates in the survey were not adjusted for the one in five who did not respond and in whom morbidity is known to be increased.

- The current analyses do not examine specific patterns of comorbidity that may be important for targeting specific treatments.

GAVIN ANDREWS, MD, World Health Organization Collaborating Centre for Mental Health and School of Psychiatry, University of New South Wales at St Vincent's Hospital, Sydney; SCOTT HENDERSON, DSc, Centre for Mental Health Research, Australian National University, Canberra; WAYNE HALL, PhD, National Drug and Alcohol Research Centre, University of New South Wales, Sydney, Australia

Correspondence: Dr Gavin Andrews, UNSW at St Vincent's Hospital, 299 Forbes Street, Darlinghurst, Sydney, NSW 2010, Australia. E-mail: gavina@crufad.unsw.edu.au

(First received 12 April 2000, final revision 2I September 2000, accepted 2I September 2000)

service delivery in Australia, exactly as found in the UK and US surveys. People normally go to the doctor when their symptoms are severe, chronic or disabling or when they think the doctor can help (Hulka et al, 1972). All with multiple or disabling disorders meet the first three criteria. Therefore, not consulting in a fully insured environment in which economic barriers are minimal might indicate a decision that the doctor cannot help. The remedy may not just be more resources, but a focus on better mental health knowledge among patients and on improving the clinical competence of practitioners. Certainly this lack of demand for appropriate help when clinical services are available is of public health importance and requires further study.

\section{ACKNOWLEDGEMENTS}

This paper benefited from a contract from the Australian Department of Health and Aged Care to the World Health Organization Collaborating Centre for Mental Health, Sydney, which supported a survey data analysis consortium (G. Andrews, V. Carr, G. Carter, R. Crino, W. Hall, A. Henderson, I. Hickie, C. Hunt, L. Lampe, A. McFarlane, P. Mitchell, L. Peters, M. Teesson and K.Wilhelm).

\section{REFERENCES}

American Psychiatric Association (1987) Diagnostic and Statistical Manual of Mental Disorders (3rd edn, revised) (DSM-III-R). Washington, DC: APA

- (1994) Diagnostic and Statistical Manual of Mental Disorders (4th edn) (DSM-IV). Washington, DC: APA

Andrews, G. (2000a) The anxiety disorder inclusion and exclusion criteria in DSM-IV and ICD-10. Current Opinion in Psychiatry, 13, 139-141.

- (2000b) Meeting the unmet need with disease management, In Unmet Need in Psychiatry (eds G. Andrews \& S. Henderson). Cambridge: Cambridge University Press.

— \& Henderson, S. (eds) (2000) Unmet Need in Psychiatry. Cambridge: Cambridge University Press.

— \& Peters, L. (1998) Psychometric properties of the CIDI. Social Psychiatry and Psychiatric Epidemiology, 33, 80-88. 
_ , Sanderson, K. \& Beard, J. (1998) Burden of disease: methods for calculating disability from mental disorder. British Journal of Psychiatry, 173, 123-13

_ , _ , Slade T., et al (2000) Why does the burden of disease persist: relating the burden of anxiety and depression to effectiveness of treatment. Bulletin of the World Health Organization, 78, 446-454.

Folstein, M. F., Folstein S. E. \& McHugh, P. R. (1975) 'Mini-Mental State': a practical method for grading the cognitive state of patients for the clinician. Journal of Psychiatric Research, 12, 189-198.

Hickie I, Hadzi-Pavlovic, D. \& Ricci, C. (1997) Reviving the diagnosis of neurasthenia. Psychological Medicine, 27, 989-994.

Hulka, B. S., Kupper, L. L. \& Cassel, J. C. (1972) Determinants of physician utilization: approach to a service-oriented classification of symptoms. Medical Care, 10, 300-309.

Jablensky, A., McGrath, J., Herrman, H., et al (2000) Psychotic disorders in urban areas. Australian and New Zealand journal of Psychiatry, 34, 221-236.

Jenkins, R., Bebbington, P., Brugha, T., et al (1997a)

The national psychiatric morbidity surveys of Great Britain - strategy and methods. Psychological Medicine 27, 765-774. $\ldots, \ldots, \ldots$, et al (1997b) The national psychiatri morbidity surveys of Great Britain - initial findings from the household survey. Psychological Medicine, 27 775-789.

Kessler, R. C., McGonagle, K. A., Zhao, S., et a (1994) Lifetime and I2-month prevalence of DSM-III-R psychiatric disorders in the United States. Archives of General Psychiatry, 5I, 8-19.

_ , Little, R. J. A. \& Groves, R. M. (1995) Advances in strategies for minimizing and adjusting for survey nonresponse. Epidemiological Review, 17, 192-204.

Kish, L. \& Frankel, M. R. (1974) Inference from complex samples. Journal of the Royal Statistical Society (Series B), 36, I-37.

Loranger, A.W., Janca, A. \& Sartorius, N. (eds) (1997) Assessment and Diagnosis of Personality Disorders. Cambridge: Cambridge University Press.

Mathers, C., Vos, T. \& Stevenson, C. (1999) Burden of Disease and Injury in Australia. AlHW cat. no. PHEI7. Canberra: Australian Institute of Health and Welfare.

Nathan, P. E. \& Gorman, J. (eds) (1998) Guide to Treatments that Work. New York: Oxford University Press.

Regier, D. A., Narrow, W. E., Rae, D. S., et al (1993) The defacto US mental health and addictive disorders service system. Archives of General Psychiatry, 50, 85-94.
Scott, J., Gilvarry, E. \& Farrell, M. (1998) Managing anxiety and depression in alcohol and drug dependence. Addictive Behaviors, 23, 919-931.

Shah, B. V., Barnwell, B. G. \& Biegler, G. S. (1997) SUDAAN User's Manual. Research Triangle Park, NC: Research Triangle Institute.

Spitzer, R. L. \& Wakefield, J. C. (1999) DSM-IV diagnostic criterion for clinical significance: does it help solve the false positives problem? American Journal of Psychiatry, 156, 1856-1864.

Tacchini, R., Janca, A. \& Issacs, M. (1995)

Neurasthenia. Geneva: Division of Mental Health, World Health Organization

Ware, J. E., Kosinski, M. \& Keller, S. D. (1996) A 12-item short form health survey. Medical Care, 34 220-233.

Woody, S., McLean, P. D., Taylor, S., et al (1999) Treatment of major depression in the context of panic disorder. Journal of Affective Disorders, 53, 163-174.

World Health Organization (1992) International Classification of Disease and Related Disorders (ICD-10). Geneva: World Health Organization.

- (1997) Composite International Diagnostic Interview - Version 2.1. Geneva: World Health Organization. 